\title{
Gilda: El coste de lanzar un guante a un oligopolista
}

\author{
ANA ROSADO CUBERo \\ Universidad Complutense de Madrid, Facultad de Comercio y Turismo, Avda. de Islas Filipinas, 3, \\ 28003 Madrid, España.E-mail: arosado@ucm.es
}

\begin{abstract}
RESUMEN
El cine es sorprendente, incluso cuando introduce de tapadillo temas económicos. En Gilda, lo que parece ser un recurso cinematográfico, en realidad lleva detrás una buena investigación en asuntos que nada tienen que ver con la trama original de la cinta. ¿Por qué el protagonista es el jefe del cartel del tungsteno y no de otro mineral? ¿Por qué el protagonista es alemán? ¿Por qué se refugia en Argentina? A lo largo del film se van respondiendo a estas preguntas, pero el guionista no tenía la mera intención de entretener con un texto plagado de frases ingeniosas, quería mostrar cómo se resuelven los conflictos económicos en los que hay mucho dinero en juego, que no es el juego del casino, aunque también.
\end{abstract}

Palabras clave: Estructura de mercado, prácticas anticompetitivas, tungsteno, economía del arte y la literatura, Gilda.

\section{Gilda: The Cost to Challenge a Cartel Member}

\begin{abstract}
Cinema is amazing, even when the sly introduces economic issues. In Gilda, what appears to be a film resource really brings back good research on issues that have nothing to do with the original plot of the film. Why is the chief protagonist tungsten cartel and not another mineral? Why the protagonist is German? Why looked for refuge in Argentina? Throughout the film are going to respond to these questions, but the writer did not intend merely to entertain with a screenplay full of one-liners, he wanted to show how to resolve economic disputes where there is big money at stake, it is not casino game though too.
\end{abstract}

Keywords: Market Structure, Horizontal Anticompetitive Practices, Tungsten, Economics of the Arts and Literature, Gilda.

Clasificación JEL: L11, L41, L64, Z11

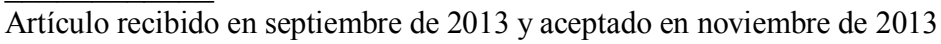

Artículo disponible en versión electrónica en la página www.revista-eea.net, ref. ə-32111 


\section{INTRODUCCIÓN}

Todos recordamos a Gilda ${ }^{l}$ quitándose un guante y lanzándolo al aire, tradicionalmente se entiende que un gesto parecido a éste significa retar a un contrincante. Pero en Gilda se lanzan varios guantes. El primero de ellos es que aparece un maverick o traidor; en términos económicos: un miembro de un cartel que se salta las normas, lo que vendría a ser un reto a los miembros del cartel. Al final comprobamos que el protagonista, Ballin Mundson un alemán emigrado a Argentina, también lanzó un guante retando a la nación alemana. Por supuesto que Johnny Farrell reta a Gilda y viceversa pero para este artículo aceptamos el reto de ver sólo los comportamientos económicos desafiantes.

En primer lugar estudiaremos lo que es un cártel y en concreto la relevancia del cártel del tungsteno como material militar y como componente básico de las bombillas, las que a su vez se fabricaron por un cártel que sobrevivió poco tiempo. Posteriormente estudiaremos cómo las patentes funcionan como barreras a la libre competencia. Un artículo sobre el tungsteno o wolframio debe hablar de sus yacimientos en España y de "la fiebre del Wolframio" de 1943, así como del acuerdo que parece que existió entre Franco y Hitler para el abastecimiento de este metal a las tropas nazis y el difícil equilibrio que el régimen español debió mantener con los aliados por el mismo asunto.

El personaje de Ballin Mundson podría ser el alter ego de Fritz Thyssen, que era el hijo del industrial y magnate alemán August Thyssen (afiliado al partido nazi de Adolf Hitler). Friedrich Thyssen trabajó para la empresa familiar y fue dado de baja en el ejército en 1914 por su mala condición pulmonar. En 1940 emigró a Francia y comenzó sus trámites de emigración a Argentina donde posteriormente se nacionalizó y vivió hasta su muerte. Lo más peculiar de su vida es que parece que lo capturaron los nazis y fue liberado en 1945; pero en 1941 se publica una "autobiografía" no autorizada en la que se reconocía so-

\footnotetext{
${ }^{1}$ Gilda narra la historia de Johnny Farrell, un jugador de poca monta que es contratado por el dueño de un casino, Ballin Mundson, para que descubra a los jugadores que hacen trampa en su casino. Al poco tiempo se había convertido en la mano derecha del dueño y le permite llevar el negocio a su manera. Cuando Ballin vuelve casado con una bella mujer, Gilda, antigua pareja de Farrell comienza el triángulo amoroso más famoso del cine de los años cuarenta. La trama económica que se oculta en esta historia consiste en que Farrell controla el oligopolio del tungsteno y ha escondido unas patentes industriales alemanas que no quiere devolver a sus legítimos dueños. Interpretada por Rita Hayworth como Gilda, George Macready como Ballin Mundson y Glenn Ford con Johnny Farrell, este último, al recibir premio Donosti del Festival de cine de San Sebastián en 1987, eligió de entre todas sus películas, que se proyectara Gilda para el homenaje.

Gilda se estrenó en España, con fuertes críticas de algunos sectores de la sociedad. Lo curioso es que el público estaba tan acostumbrado a ver las películas en el cine con tantos cortes de escenas hechos por la censura que se rumoreaba que Rita Hayworth continuaba desnudándose después de quitarse el guante pero que las imágenes habían sido pasto de las tijeras.
} 
porte económico del partido nazi. Indudablemente un personaje así reúne todas las características con las que cualquier guionista ${ }^{2}$ de Hollywood podría soñar, no olvidemos que Gilda es de 1946.

\section{EL OLIGOPOLIO DEL TUNGSTENO}

Empezaremos por el primer guante que se lanza en Gilda retando al jefe del cartel del tungsteno. Alguien recibe un dinero en el casino apostando 1000 pesos al dos negro a la ruleta. Un señor bajito, muy humilde en su vestimenta y que despierta lástima entre los espectadores entra sin hacer ruido en un casino bonaerense, mira al croupier y recibe un guiño como respuesta, todos entendemos que afirmativa, y coloca sus fichas en un número que resulta ser ganador. Se acaba la guerra, todos suponemos que se trataba de la segunda guerra mundial y la escena de la apuesta se repite, pero en esta ocasión al señor bajito no se le acepta la apuesta y es conducido a la oficina del casino donde se le increpa para que desista de su actitud. El jefe del Cartel, Mundson, le recuerda que sus pérdidas empresariales han sido pagadas por las mesas del casino, regular y generosamente, y que a pesar de sus órdenes sigue vendiendo tungsteno a la compañía "Bendolin", a lo que el socio minoritario contesta que "Bendolin" no puede hacer bombillas sin cables de tungsteno para los filamentos (Gilda, 1946: min. 36), Mundson le replica que no puede continuar con su negocio, la conversación continúa así:

"Mundson.- Nosotros no queremos que continúe el negocio del señor "Bendo-

Oligopolista pequeño.- "Bendolin" es la única salida para mi producto en este territorio, si no puedo venderle, yo no puedo continuar, ¿es que no lo comprende?

Mundson.- la vida es dura para la gente indefensa" (Gilda, 1946: min. 37)

Esta protesta le cuesta la vida ya que el pequeño oligopolista dispara a Mundson y posteriormente se suicida.

Veamos el trasfondo económico que desenmaraña este turbio asunto. Los economistas definimos tres tipos de estructuras de mercado, a saber: cuando sólo hay un oferente que controla el mercado lo llamamos monopolio, si hay muchos oferentes que no pueden controlar el mercado lo llamamos competencia perfecta, y si unos pocos productores se reparten el mercado lo llamamos oligopolio. Podemos subdividir esta última categoría en dos tipos de oligopolio; la primera en la que todos los miembros del oligopolio participan en el reparto del

\footnotetext{
${ }^{2}$ Poco se sabe de los tres guionistas de la película, Marion Parsonnet, Jo Eisingen y E. A. Ellington. Parsonnet se especializó en películas románticas y Ellington en musicales y televisión. El especialista en cine negro era Eisinger, y obtuvo un gran reconocimiento por Gilda y por Night and the city, desde los años 60 se dedicó a escribir para programas de televisión obteniendo un Edgar Award en 1984.
} 
mercado para controlar el precio, se conoce como cartel y la OPEP es un buen ejemplo. El otro subtipo se caracteriza porque un selecto grupo de productores, no más de cinco, impone las normas y actúan de paraguas ${ }^{3}$ sobre los otros productores más pequeños, sobre todo controlando que el precio del mercado esté por encima de los costes marginales; este tipo es característico de los productores de inputs básicos y caros de transportar, como el cemento.

El primer tipo de oligopolio ${ }^{4}$ mantiene un equilibrio endeble mientras todos los miembros mantengan su cuota de mercado; si ninguno inunda el mercado de petróleo, el precio estará controlado por los países extractores de petróleo. Claro está que la tentación es grande, pues mientras nadie te descubra puedes vender más de tu cuota y tener unos ingresos extras. Mientras el maverick no abuse, la probabilidad de ser descubierto es baja. El castigo del grupo puede desincentivar este comportamiento ya que si te expulsan no sólo pierdes el "mejor precio" sino que también puedes perder tus antiguos clientes contentos con el cartel y que les garantiza el abastecimiento aunque un poco más caro. Los carteles de este tipo suelen tener un fondo de compensación por si el precio negociado no permite sobrevivir a los más débiles.

El segundo tipo de oligopolio se mantiene en equilibrio porque los pequeños productores se benefician al conseguir precios que les permiten cubrir costes; este precio no lo conseguirían en un mercado de libre competencia. Ni que decir tiene que los selectos cinco obtienen beneficios extraordinarios, ya que el precio de venta al cliente cubre sus costes sobradamente además de aportarles unos beneficios extras.

Económicamente hablando, en cualquier mercado da lo mismo que los oligopolistas controlen la cantidad ofertada o el precio, ya que el resultado siempre es un perjuicio al cliente si el oligopolio es de un input básico o al consumidor si el cartel es de un producto de venta final.

El tipo de oligopolio ${ }^{5}$ que se muestra en Gilda es el del tungsteno como input básico y material estratégico, imprescindible por ejemplo en la fabricación de bombillas en su uso civil; pero en su uso militar, el tungsteno es un metal duro como el diamante. El carburo de tungsteno o carburo de wolframio es un compuesto cerámico de gran dureza, se emplea en la fabricación de maquinarias y utensilios de acero y máquinas para trabajar el acero. Este tipo de materiales

\footnotetext{
${ }^{3}$ Este tipo de oligopolio fue definido por George Stigler en los años cincuenta.

${ }^{4}$ Para una modelización teórica del comportamiento oligopolístico consultar Arranz Sombría, MR. (2011), "Cooperación en modelos de Cournot con información incompleta" en Estudios de Economía Aplicada, 29 (1), pp. 1-18.

${ }^{5}$ La misma línea argumental se puede emplear para otros oligopolios, ver ARNEDILLO BLANCO, O. (2011). "¿Es competitivo el mercado eléctrico español? Indicadores de abuso de poder de mercado y aplicación al caso de España”, en Estudios de Economía Aplicada, 29 (2), pp. 627-654.
} 
se conoce como cermets o ceramic metal. Además tiene el punto de fusión más elevado de todos los metales $\left(3.422^{\circ} \mathrm{C}\right)$ y una alta densidad; el wolframio es muy estable térmica y químicamente y es un excelente conductor. Resumiendo es el material más duro presente en la naturaleza (después del diamante) y es bastante respetuoso con el medio ambiente.

El wolframio actualmente se emplea en la fabricación de bombillas, tubos fluorescentes, "ahorradores de energía", lámparas HID, teléfonos móviles, televisores, magnetrones para hornos microondas y otros productos de electrónica de consumo. Asimismo, se utiliza para fabricar las herramientas que taladran paredes, cortan baldosas y afilan cuchillos e incluso se usa para fabricar las bolitas de la punta de los bolígrafos.

En 1897 aparecieron las primeras pruebas de que el wolframio mezclado con azúcar (por el carbono) era un material muy duro pero muy frágil, de ahí que no fuera muy útil para la industria. En 1923 Osram, la empresa berlinesa fabricante de bombillas, sintetizó el carburo de wolframio con un 10\% de cobalto, y la aleación resultante permitió su uso industrial. El fabricante alemán de acero, Krupp, a la sazón proveedor de Osram, compró los derechos de producción de la aleación en 1925.

De este modo se resolvía el viejo problema de la industria de principios del siglo XX, que era encontrar núcleos de diamante, los cuales además de ser caros, tenían sus yacimientos en África; pero por entonces Alemania había perdido sus colonias en dicho continente.

Krupp patentó el nuevo material con la denominación WIDIA (Wie Diamant, que traduce "como diamante") después de una batalla legal con Walter, una empresa tubinguesa que había desarrollado un material parecido. La compensación para Walter fue que Krupp no fabricaría herramientas de fresado en 40 años.

Por su parte, los americanos de General Electric habían desarrollado su propia aleación para un metal duro. Hacia 1930 lo habían conseguido. Durante los años treinta, Krupp y General Electric llegaron a un acuerdo de reparto del mercado, donde Krupp se comprometía a no entrar en Norteamérica y General Electric haría lo propio en el mercado europeo.

La competencia por los "metales duros" en Europa cada vez era más intensa, los Austríacos de Plansee, los suecos de Fagersta, e incluso una empresa americana, Kennametal, que se enfrentó al cartel alemán-americano que pretendía repartirse el mercado y -simplemente aprovechando "la mala fama" del competidor- se hizo con un trozo de la tarta; Kennametal se aprovechó de las acusaciones de colaboracionismo de General Electric con el ejército alemán, para suministrar al ejército americano la munición y los blindajes que necesitaba para su tanques Sherman. Durante el principio de los años 30 en Düsseldorf (Alemania), así como en Francia, Suiza, Inglaterra y Japón se producen aleacio- 
nes de metales que técnicamente son metales duros; Suecia se une a la carrera en 1942 e Israel en 1952. La guerra de las patentes está servida, pero de este asunto hablaremos después.

La otra gran batalla eran las bombillas, su desarrollo y patentes; y por supuesto también tuvieron un cartel. En 1924 se funda el cartel conocido como Phoebus al que pertenecían Osram, Philips, Tungsram, Associated Electrical Industries, ELIN, Compagnie des Lampes (Mazda), International General Electric, Lámparas "Z" de España y el GE Overseas Group. Todas las empresas eran propietarias de un paquete de acciones de la empresa suiza proporcional a las ventas de sus productos. Pero esta guerra la pierden, en 1931, pues los escandinavos fabricaban y vendías bombillas a un precio bastante más bajo que Phoebus. Aunque el acuerdo se firmó hasta 1955, la segunda guerra mundial anticipó acontecimientos y el cartel no sobrevivió; aún quedaban rescoldos para que en 1948 las empresas intentaran revivir los acuerdos, pero ya fue muy difícil.

Ahora sabemos la importancia del tungsteno y el trasfondo que escondía el diálogo entre Mundson y Farrell.

"Mundson.- Dirijo el cartel de un producto estratégico que puede controlar el mundo

Farrell.- El mundo es un lugar muy grande

Mundson.- Compuesto por estúpida gente pequeña" (Gilda, 1947: min. 43)

Mundson no controlaba un cartel de un input primario, si no el cartel del metal que haría ganar la segunda guerra mundial al país al que Mundson decidiera vender el tungsteno.

El primer guante que se lanza en Gilda es el reto de un oligopolista pequeño al cartel que no le deja vender su producción de tungsteno. Como se ve, el señor bajito había traicionado al cartel del tungsteno vendiendo su producto, mientras que los miembros del cartel le pagaban porque no lo hiciera. Él se había comportado así porque su cliente le pedía más producción y si no le abastecía la empresa de su cliente no podría seguir funcionando y él tampoco. Por tanto el control del input incluye no solo la cantidad que se vende a los clientes sino también a qué clientes. Tal vez "Bendolin", la empresa de bombillas de la película, se había negado a pagar el precio establecido por el cartel y había buscado un abastecedor externo, y por tanto un traidor. En este ejemplo se ilustra como el respeto a las cuotas en un oligopolio es básico para mantener los beneficios del cartel (y el control de un input estratégico). Pero el acuerdo de reparto de la producción entre los productores no se puede firmar en un contrato, sino que se resuelve con un pacto entre caballeros, lo que imposibilita que el agente que sufre una afrenta recurra a un juez. Una multa o la expulsión del maverick del cartel suele ser la consecuencia de su desafío; no obstante el asesinato siempre es más melodramático y en el cine atrapa mejor al espectador. 


\section{BARRERAS A LA LIBRE COMPETENCIA: LAS PATENTES}

El segundo comportamiento desafiante es la negativa del protagonista -Ballin Mundson- a devolver todo lo que la organización secreta que controlaba el cartel del tugnsteno había puesto a su nombre. En la película se ve que un buen día aparecen en el casino dos personajes con claro aspecto alemán y aún más claro comportamiento germánico de la época: rudos, agresivos y hablando con mucha autoridad. El espectador ve claramente lo que imagina, es decir, que deben ser los mensajeros de un nazi.

Sospechamos que se trata de alemanes nazis y que al final de la segunda guerra mundial querían recuperar sus propiedades, escondidas a nombre de Mundson. Uno de estos individuos aparece muerto en el casino y Mundson tiene que cambiar sus planes; en primer lugar, decide dejar a Farrell como heredero y le da instrucciones acerca de cómo abrir una caja fuerte donde encontrará unas cartas firmadas con instrucciones; poco después, finge su muerte para dejar de ser perseguido.

Farrell abre la caja fuerte y descubre que es el dueño de una mina de tungsteno, unas pocas patentes y una docena de pequeñas empresas; todo junto era un gran conglomerado empresarial y entonces se da cuenta del poder que tiene. En palabras de Farrell "que podía crecer y levantarse contra alguien que quisiera enfrentarse" (Gilda, 1946: min. 76). Farrell se reúne con los otros 12 miembros del cartel para decirles que nada va a cambiar y, ante las protestas de algunos de ellos, concluye que "solo uno debe dirigirlos" (Gilda, 1946: min. 77).

En otra escena de la película el mensajero alemán que continúa vivo informa a Farrell de que "las patentes pertenecen a los principales" (Gilda, 1946: min. 80), lo que nos deja ver que Mundson no era uno de las cinco grandes empresas mineras del cartel. El mensajero explica a Farrell que le dieron permiso a Mundson para comprar las patentes (y le adelantaron el dinero) con el acuerdo de que las devolvería después de la guerra en un "pacto entre caballeros". La respuesta de Farrell es que conoce el pacto pero deja claro que no lo va a cumplir.

Por otra parte, la policía argentina está interesada en conocer los nombres de los socios del cartel. Incluso el detective Maurice Obregón le dice a Farrell: "puedo esperar más que usted tengo la ley de mi parte" (Gilda, 1946: min. 93). Pero también le informa de que los alemanes quieren las patentes y los acuerdos firmados por Mundson. Lo curioso es que todos están siendo perseguidos por romper las reglas anti-trust, lo que viene a ser: perseguidos por los americanos, los adalides por excelencia del anti-trust. Debido a que Argentina no participó en la segunda guerra mundial, parece un país idóneo para esconder las patentes $\mathrm{y}$ al dueño de las mismas. 
Veamos el trasfondo económico de lo que realmente buscaban los personajes que hacen de mensajeros de los alemanes. Las patentes son las mejores barreras de entrada a cualquier industria, es decir, el modo más rápido de impedir que un competidor entre en tu mercado y te quite tus clientes. La entrada de nuevos competidores en cualquier mercado hace bajar los precios al haber más empresas ofreciendo el mismo producto, a no ser que haya un acuerdo de precios y el nuevo se sume al trato o, como en este caso, haya una patente que directamente impide que una empresa opere en ese mercado.

Las barreras a la competencia desarrolladas por las empresas a lo largo de la historia han sido muchas y algunas muy ingeniosas, desde la concesión de la explotación de alumbre que el Papa concedió a los Medici en la Edad Media, (de forma que todo quedó en casa), hasta las más modernas patentes de las farmacéuticas que tanto juego dan en el cine.

Según la Real Academia de la Lengua, una patente de invención es un documento en el que oficialmente se le reconoce a alguien una invención y los derechos que de ella se derivan. Es decir, una patente es un acuerdo entre un inventor y un país, por el que una invención se inscribe en un registro de patentes y otorga al titular de la misma el derecho de impedir que terceros hagan uso de la tecnología patentada -tanto su fabricación como su uso o su venta- por un tiempo limitado. El inventor, por su parte, está obligado a la divulgación de la invención de tal modo que ésta sea reproducible por un experto en la materia.

Como vimos al principio de este artículo, la guerra de los descubrimientos sobre las aplicaciones del tungsteno se libró entre los años treinta y cuarenta del siglo XX. La primera patente de una bombilla es de 1880, pero la bombilla Osram que se fabricaba con filamentos de tungsteno es de 1923. Los competidores principales de Osram eran Philips y General Electric y al ser pocas empresas en un mercado fue más rentable el intercambio de patentes a ambos lados del Atlántico y repartirse el mercado que competir. Es decir, el cartel acordaba los precios y sin competencia éstos no bajan; además de que si compartían las patentes, ninguna empresa nueva podría fabricar bombillas en Europa o Estados Unidos y hacerles la competencia: el negocio era redondo.

Las patentes mantenían la exclusividad de la fabricación durante unos años, por regla general unos veinte, en Alemania en este periodo. Veinte años era una buena ventaja en la fabricación sobre tus más directos competidores.

Sin olvidar que según una lista de la revista Life, la bombilla fue la segunda patente más útil de las invenciones del siglo XIX después de las cerillas. Ni que decir tiene la transcendencia e importancia estratégica de las aplicaciones militares. El desarrollo tecnológico de uso militar no suele protegerse con patentes, más que nada porque ninguna empresa que no disponga de acuerdos para la fabricación de las armas puede hacerlo, luego no tiene sentido una patente militar; lo que tiene razón de ser es un fuerte dispositivo anti-espionaje. 
Después de ver la película, todos sospechamos que Mundson se llevó a Argentina algunas de las patentes más relevantes de uso civil, pero los mensajeros y la persecución de la policía argentina nos hacen sospechar que tal vez algunas de esas patentes pudieran tener uso militar.

Por otra parte, entre las capitulaciones alemanas de la segunda guerra mundial está la imposición americana de la desaparición de los carteles y el fomento de la libre competencia. Los carteles alemanes eran grandes empresas formadas por bancos e industrias que habían permitido el desarrollo industrial alemán. Los carteles permitieron la consecución de economías a escala en la fabricación de productos, además del acceso al crédito que la industria requería para afrontar grandes inversiones. Pero la esencia del cartel encerraba la expulsión de los pequeños productores, el control de las materias primas y un sinfín de privilegios. Al final de la gran contienda, los americanos vieron en este modo de organización empresarial una amenaza, lo llamaban gigantismo y en los Estados Unidos estaba perseguido bajo la Ley Sherman y sucesivas normativas y que en su conjunto se conocieron como legislación anti-trust. El anti-trust incluye a la Comisión Federal de Comercio, que es la organización de consumidores y que persigue cualquier abuso de posición dominante en un mercado. A los ojos de un americano un cartel implica el ejercicio de posición dominante, y por tanto la policía argentina lo que quería era el nombre de los componentes del cartel del tungsteno para desactivar dicho cartel persiguiendo cualquier comportamiento abusivo.

\section{ESPAÑA Y EL WOLFRAMIO O TUNGSTENO}

Esta película nos permite hacer unos breves comentarios sobre el tungsteno (que en España se llama wolframio) y la historia económica española. El 6 de agosto de 1944, el diario ABC publicaba un anuncio "Se vende una mina de wolframio con guía, en término de Garrovillas, a dos kilómetros del pueblo. Para tratar: Santos Domínguez, Garrovillas (Cáceres)". Un anuncio tan peculiar merece una breve investigación. Parece ser que durante los años 40, los aliados compraban el wolframio en el mercado libre a cualquier precio por eso se incrementó su precio y con ello, los ingresos por exportaciones para una economía maltrecha. El año 1943 se conoce como el año de la "guerra del wolframio", lo cual debió propiciar el anuncio de ABC.

Poco se sabe del wolframio en España. Hay minas aunque no grandes, la mina más grande se llama la Parrilla y está en Almoharín (Cáceres), y también hay minas de cierta relevancia en la sierra de Gata y otras más pequeñas repartidas por todo el territorio. La calidad de wolframio no es muy buena, aunque esto durante la segunda guerra mundial no debió ser muy relevante, si tenemos en cuenta su valor militar. 
El profesor Payne, de la universidad de Wisconsin-Madison, recoge en su libro sobre Franco y Hitler un acuerdo comercial en los siguientes términos:

"Se negoció un nuevo tratado comercial que estaría vigente entre el 1 de diciembre de 1943 y el 30 de noviembre de 1944, en virtud del cual Alemania podría importar bienes por valor de 335 millones de marcos de España, de los cuales el importantísimo wolframio supondría un mínimo de 127 millones ${ }^{\prime \prime}$.

El artículo de Caruana y Rockoff recoge la evolución de los precios y la cantidad extraída de wolframio en España entre 1911 y 1955, y ratifica el fuerte incremento de la producción entre 1942 y 1945 y una subida espectacular de los precios de este metal en 1940; bien es cierto que el derrumbe es colosal en 1944. Por tanto, se puede sostener que en España se produjo una "fiebre del wolframio" en ese periodo.

En la actualidad el wolframio no ha dejado de ser relevante. Así, el 17 de julio de 2012 el departamento de defensa americano sacó a la venta una parte de sus stocks de tungsteno. Incluso en 2013 leyendo los periódicos nos encontramos con el wolframio gallego: Rubén Rodríguez, desde economíadigital.es denuncia que el wolframio sale de la mina y se exporta sin elaboración hacia los mayores compradores que son China y Estados Unidos; y estos países, a su vez, exportan la materia prima en forma de componentes.

\section{CONCLUSIONES}

El presente artículo se ocupa de analizar los entramados económicos que subyacen debajo de una de las mejores películas de todos los tiempos. De hecho, su protagonista, Gilda, tiene un nombre propio en el cine, tanto como la actriz que la representó, Rita Hayworth.

Los acuerdos de empresa y las amenazas entre competidores son muy comunes en el mundo de los negocios, todo en función de los beneficios, y esa maraña de personajes sórdidos son una fuente inagotable de protagonistas para las películas de Hollywood; un buen ejemplo de ello es Gilda, pero hay muchos más. Lo que hace a esta película superior a la media es que se escribe y se proyecta durante la mayor guerra del siglo XX, y la trama económica se centra en un material estratégico, el tungsteno o wolframio.

Espero que al final de este artículo, el lector aún tenga ganas de volver a ver Gilda y cómo Rita Hayworth enreda lentamente un guante en su brazo, para después recibir la bofetada con más renombre de la historia del cine. Pero sin dejar de prestar atención a cómo la película encumbra a un jugador de medio pelo al estatus de jefe absoluto de un cartel en el que los cabecillas son nazis alemanes.

\footnotetext{
${ }^{6}$ Payne, Stanley G. (2008). Franco y Hitler. Pp 306.
} 


\section{REFERENCIAS BIBLIOGRÁFICAS}

ARNEDILLO BLANCO, O. (2011). “¿Es competitivo el mercado eléctrico español? Indicadores de abuso de poder de mercado y aplicación al caso de España”, en Estudios de Economía Aplicada, 29 (2), pp. 627-654.

ARRANZ SOMBRÍA, MR. (2011). "Cooperación en modelos de Cournot con información incompleta" en Estudios de Economía Aplicada, 29 (1), pp. 1-18.

AZEVO, C. DEL (2012): "Sierra de Gata, el retorno del wolframio", http://www.sierradegatadigital.es. 15 abril.

CARUANA L. AND ROCKOFF H. (2003). "A Wolfram in Sheep's Clothing: Economic Warfare in Spain", 1940-1944, en The Journal of Economic History, 63 (1), pp. 100126.

GABSZEWICZ, J. J. AND THISSE, J. F.(1999). Microeconomic theories of imperfect competition, old problems and new perspectives. Northampton: Edward Elgar.

GREENWALD B. AND KAHN J. (2005). Competition Demystified. New York: Porfolio.

http://en.wikipedia.org/wiki/Fritz_Thyssen

http://saloro.com/es/tungsten/about-tungsten/tungsten_uses

http://sigeo.gobex.es/portalsigeo/web/guest/geologia-y-recursos-minerales

http://www.rae.es/rae.html

JONNES. J. (2010): "Let There Be Light”, en Time. Wednesday, June 23.

KILZER, L. (2012): "Strategic tungsten stockpile available": http://triblive.com, June 17.

LANNING S. G. (1987). "Cost of Maintaining a Cartel" en The Journal of Industrial Economics, 36(2), pp. 157-174.

PAYNE, S. G. (2008). Franco y Hitler. Madrid: La esfera de los libros.

PORTER, M. E. (1980). Competitive Strategy: Techniques for Analyzing Industries and Competitors. New York: The Free Press.

RODRÍGUEZ, R. (2013). "El wolframio de Galicia busca compradores en China y EEUU", http://www.economiadigital.es, 07/02/2013.

ROSADO-CUBERO, A. (2010). Barriers to competition. London: Pickering and Chatto.

SCHMALENSEE, R. WILLIG R. (Ed.) (2001). Handbook of Industrial Organization. Amsterdam: Elsevier Science B.V.

STIGLER, G. (1950). "Monopoly and Oligopoly by Merger" en The American Economic Review, 40 (2), pp. 23-34.

WILLIAMSON, O. E. (1987). Antitrust Economics: Mergers, Contracting, and Strategic Behaviour. New York: Basil Blackwell Inc. 
